\title{
NGHIÊN CỨU XÂY DỰNG BẢN ĐỒ CHỈ SỐ ĐỘ ẨM KHU VỤ̉C TỈNH BẾN TRE TỬ ẢNH VỆ TINH SENTINEL-1
}

\author{
HOÀNG MINH HẢI ${ }^{(1)}$, VƯỚ TRỌNG KHA ${ }^{(2)}$ \\ (l)Viện Khoa học Đo đạc và Bản đồ \\ (2) Truoòng Đại học Mó - Địa chất
}

\section{Tóm tắt:}

Bộ cảm SAR trên vệ tinh Sentinel-1 là bộ cảm chủ động hoạt động trong băng tần $C$ (tù 4 đến 8 GHz) của dải quang phổ điện tù̀, không chịu ảnh hưởng bởi các yếu tố thời thiết hay điều kiện ngày đêm. Thông tin thu nhận được trên ảnh, hay còn được gọi là giá trị tán xạ ngược của tín hiệu radar, có mối tương quan với giá trị độ ẩm đất. Bài báo này trình bày kết quả nghiên cứu thành lập bản đồ độ ẩm đất tù dũ liệu ảnh vệ tinh Sentinel-1. Để tính toán thực nghiệm cho việc thành lập hàm phù hợp (hồi quy) thể hiện mối quan hệ toán học giữa giá trị độ ẩm đất đo thực tế với các giá trị được chiết tách tù các điểm tương úng trên ảnh tán xạ ngược ở phân cưc VV đã được lựa chọn. Trong nghiên cưu này, tác giả đã tiến hành nghiên cứu khả năng sủ dụng ảnh Sentinel-1 (băng tần C) kết hợp với dũ liệu đo độ ẩm đất ngoài thực địa (cùng hay gần thời điểm với ảnh được chup) để xây dưng thành lập bản đồ độ ẩm đất trên khu vục tỉnh Bến Tre.

\section{Mở đầu}

Trên thế giới, việc ứng dụng dữ liệu viễn thám hồng ngoại nhiệt trong nghiên cứu và giám sát hạn hán đã đạt được những kết quả quan trọng $[4,5,7]$. Ở Việt Nam, một số nghiên cứu đã sử dụng ảnh nhiệt MODIS, NOAA/AVHRR trong xác định độ ẩm đất dựa trên mối quan hệ giữa nhiệt độ bề mặt và các loại hình lớp phủ [8]. Tuy nhiên, độ phân giải không gian của ảnh MODIS, NOAA/AVHRR là rất thấp, độ chính xác không cao và không thích hợp cho các nghiên cứu chi tiết. Ảnh hồng ngoại nhiệt LANDSAT với độ phân giải không gian 120m (TM), 60m (ETM+), 100m (LANDSAT 8) cung cấp thông tin rõ ràng hơn về sự thay đổi nhiệt độ mặt đất so với ảnh MODIS, NOAA/AVHRR, do vậy có thể được sử dụng hiệu quả trong nghiên cứu tình trạng khô hạn bề mặt Trái Đất [9]. Bộ cảm SAR trên vệ tinh Sentinel-1 là bộ cảm chủ động hoạt động trong băng tần $\mathrm{C}$ (từ 4 đến 8 $\mathrm{GHz}$ ) của dải quang phổ điện từ, không chịu ảnh hưởng bởi các yếu tố thời thiết hay điều kiện ngày đêm. Nhiều nghiên cứu đã chứng minh khả năng thành lập bản đồ độ ẩm đất từ các ảnh radar thuộc băng tần $\mathrm{X}[1]$, hay thuộc băng tần $\mathrm{C}$ $[2,3]$ và trên băng tần $\mathrm{L}[6]$.
Bài báo này trình bày kết quả nghiên cứu thành lập bản đồ độ ẩm đất từ dữ liệu ảnh vệ tinh Sentinel-1. Để tính toán thực nghiệm cho việc thành lập hàm phù hợp (hồi quy) thể hiện mối quan hệ toán học giữa giá trị độ ẩm đất đo thực tế với các giá trị được chiết tách từ các điểm tương ứng trên ảnh tán xạ ngược ở phân cực VV đã được lựa chọnđể xây dựng thành lập bản đồ độ ẩm đất trên khu vực tỉnh Bến Tre.

\section{Phương pháp nghiên cứu}

\subsection{Phưong pháp xử lý ảnh radar}

\section{Bước 1: Loại bỏ nhiễu (Noise Removal)}

Việc loại bỏ nhiễu là khâu quan trọng cần luôn được thực hiện khi xử lý các loại ảnh radar.Mục đích là nhằm loại bỏ các tín hiệu radar bị nhiễu động bởi các yếu tố môi trường xung quanh.

\section{Bước 2: Hiệu chinh tán xạ (Calibration)}

Đểchuyển giá trị của các pixel ảnh về giá trị tán xạ ngược được hiệu chỉnh bức xạ thì cần sử dụng các thông tin cần thiết đã được cung cấp trong metadata của ảnh để chuyển giá trị cường độ sang giá trị Sigma0 
được thực hiện theo công thức sau:

$$
\sigma^{\circ}=\frac{D N^{2}}{A_{\sigma}^{2}}
$$

Trong đó: DN là giá trị số (digital number) của độ xám nguyên gốc; $A_{S g}^{2}$ là diện tích thiết diện quy chiếu của bề mặt tán xạ.

\section{Buớc 3: Lọc dĩ liệu (Filter)}

Nhiễu Speckle là nhiễu đặc trưng luôn có trên các loại ảnh radar, hoàn toàn ngẫu nhiên và do bộ cảm không nhận được tín hiệu phản hồi (tán xạ) từ đối tượng có tín hiệu bị phân tán mạnh, hoặc do bộ cảm nhận được tín hiệu phản hồi cao bất thường (cực đại) từ các đối tượng có tín hiệu giao thoa với nhau tại một vị trí bất kỳ trên ảnh. Vì vậy, việc sử dụng bộ lọc để loại bỏ các đốm này trên ảnh radar là cần thiết để giúp làm tăng chất lượng hình ảnh và nâng cao độ chính xác trong khi phân tích ảnh.

\section{Bước 4: Nắn chỉnh hình học}

Một trong những đặc điểm đặc trưng của ảnh radar là biến dạng địa hình. Vì vậy việc nắn chỉnh hình học cho ảnh radar cũng là yêu cầu bắt buộc. Việc nắn chỉnh này cần dựa vào các thông số được cung cấp trong metadata của ảnh và mô hình số độ cao.

\section{Bước 5: Trích xuất khu vực nghiên cưu}

Kích thước của một cảnh ảnh radar Sentinel1 là rất lớn, $250 \mathrm{~km}^{2}$, do vậy để giảm dụng lượng lưu trữ và thời gian xử lý, dữ liệu khu vực nghiên cứu được trích xuất bằng chức năng Subset của phần mềm SNAP 6.0. (Xem hình 1)

\subsection{Phương pháp xử lý ảnh lấy mẫu}

Trên cơ sở tọa độ các điểm được lấy mẫu ngoài thực địa, tại mỗi vị trí của điểm mẫu, thông tin về độ ẩm đất và thông tin tán xạ ngược của các phân cực $(\mathrm{VV}, \mathrm{VH})$ và góc tới cục bộ (PLIA) từ ảnh Sentinel-1 (sau khi xử lý) sẽ được trích xuất. Như vậy, mỗi điểm mẫu sẽ chứa thông tin về độ ẩm đất và tán xạ ngược của các phân cực VV, VH, cũng như giá trị góc tới cục bộ PLIA. Dữ liệu được chiết tách cho các điểm mẫu được tiến hành trên ảnh được thu ngày 25 tháng 4 năm 2019 (dữ liệu đo đạc thực địa được thực hiện từ ngày 24 đến ngày 26 tháng 4 năm 2019).

\subsection{Xác định mối quan hệ giữa tán xạ ngược và góc tới cục bộ với độ ẩm đất}

Mối quan hệ giữa tán xạ ngược radar và góc tới cục bộ với độ ẩm đất được xác định dựa trên biểu đồ dạng đường và đám mây điểm. Dựa vào sự phân bố của đám mây điểm để xác định mô

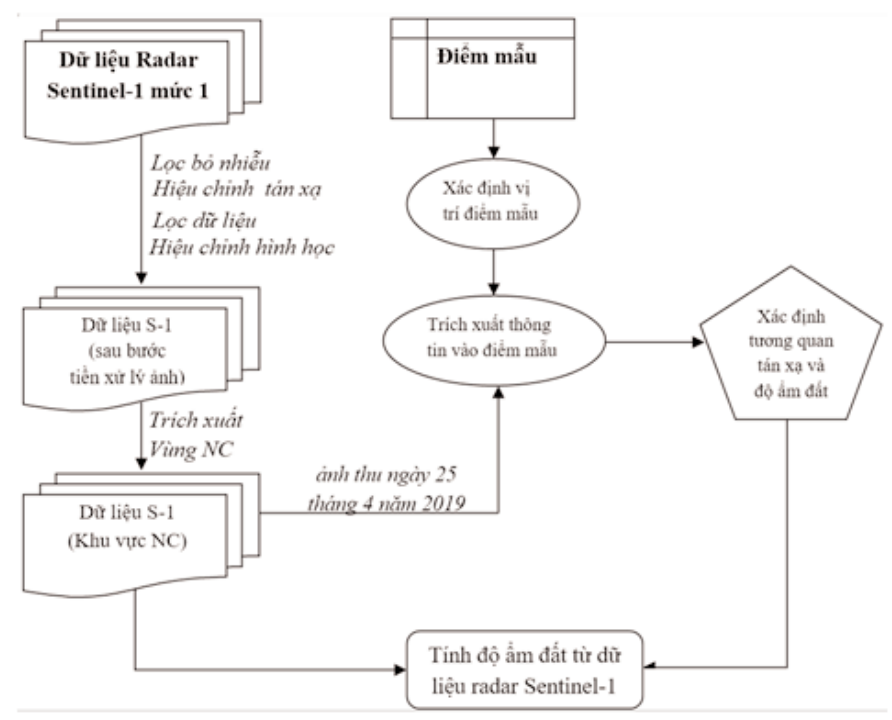

Hình 1: Quy trình xủ lý ảnh radar Sentinel-1 trong thành lập bản đồ độ ẩm đất 
hình tương quan giữa các yếu tố ghi nhận được trên ảnh Sentinel-1 ở các phân cực và góc tới cục bộ với giá trị độ ẩm đất được đo đạc trong phòng thí nghiệm (trên cơ sở các mẫu đất được lấy trực tiếp ngoài thực địa), từ đó xác định được phương trình tương quan và hệ số tương quan $\mathrm{R}^{2}$. Dựa trên phương trình tương quan này ta có thể tính toán giá trị độ ẩm đất cho tất cả các pixel còn lại trên ảnh.

\subsection{Thông tin về dĩ liệu ảnh Sentinel-1 được sử dụng trong nghiên cúu}

Dữ liệu Sentinel-1 thu ngày 25 tháng 4 năm 2019, 24 tháng 4 năm 2018 và 22 tháng 4 năm 2016, mức xử lý 1 gồm phân cực VV và $\mathrm{VH}$ độ phân giải không gian $5 \times 20 \mathrm{~m}$, kích thức pixel ảnh được tái chia mẫu về kích thước $10 \times 10 \mathrm{~m}$.

2.5. Thông tin về vị trí và giá trị độ ẩm đất tuơng ứng đo trục tiếp tù̀ mẫu đất lấy tại thục dịa

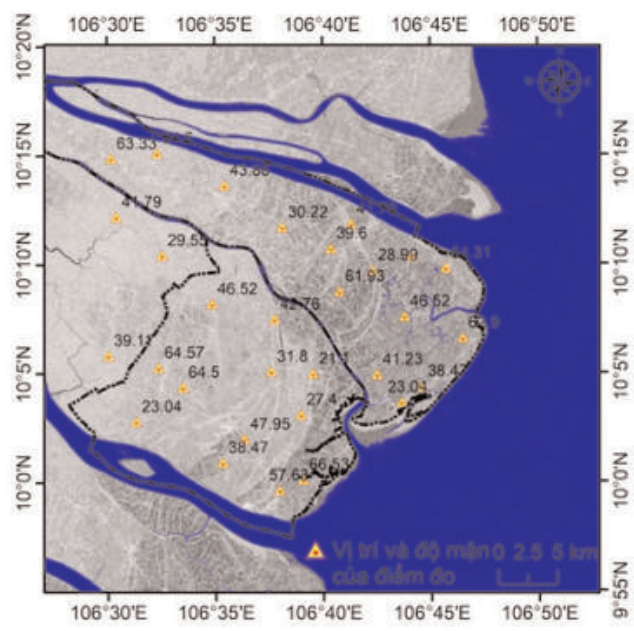

Hình 2: Vị trí các điểm lấy mẫu để đo độ ẩm đất được chồng xếp lên ảnh Sentinel-1

Tổng số 30 điểm mẫu được lấy phân bố đều trên khu vực nghiên cứu (hình 2). Số liệu đo ẩm đất được chiết tách trong phòng thí nghiệm cho từng điểm mẫu được mô tả như trong bảng 1 .

\section{Kết quả nghiên cứu}

\subsection{Kết quả tính toán ảnh phân cục, góc tới cuc bộvà độ ẩm đấttù̀ ảnh Sentinel-1}

(Xem hình 3, bảng 1, hình 4)

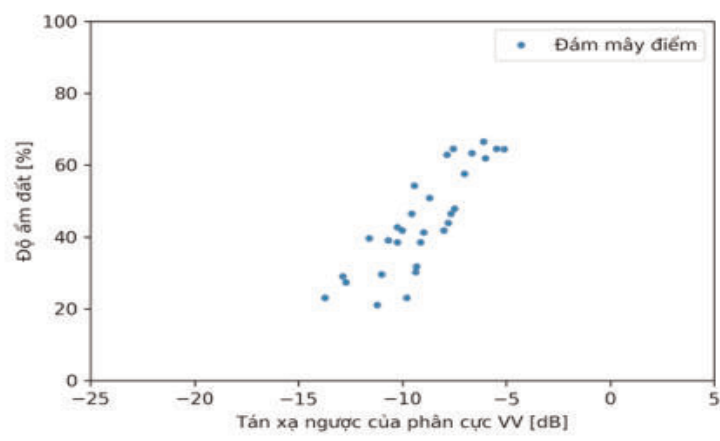

Hình 4: Scatter plot giũa giá trị độ ẩm đất (đo trong phòng thi nghiệm) với giá trị tán xạ ngược được chiết tách tù các ảnh phân cưc VV

Kênh ảnh Sentinel-1 ở phân cực VV được lựa chọn để tính toán thực nghiệm cho việc thành lập hàm phù hợp (hồi quy) thể hiện mối quan hệ toán học giữa giá trị độ ẩm đất đo thực tế với các giá trị được chiết tách từ các điểm tương ứng.Hàm tuyến tính bậc 1 được sử dụng để mô hình hóa mối quan hệ toán học này là : Độ ẩm = $5.4 \times$ Sigma $_{\mathrm{vv}}+94.3$

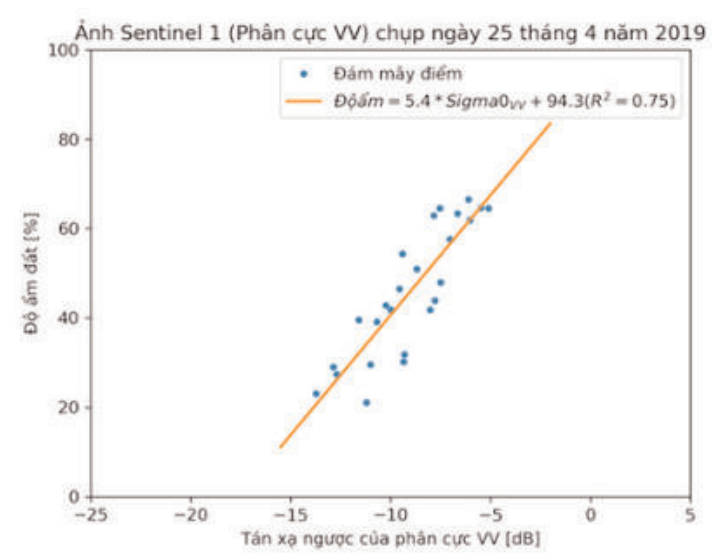

Hình 5: Tưong quan tuyến tính (bậc 1) giữa giá trị độ ẩm đất (\%) với giá trị tán xạ ngược của ảnh Sentinel-1 (phân cục VV, thu ngày 25 tháng 4 năm 2019)

Áp dụng công thức hàm hồi quy (1) để xây dựng ảnh thể hiện độ ẩm đất cho 3 thời kì: $25 / 4 / 2019,24 / 4 / 2018$ và 22/4/2016. Kết quả như sau: (Xem hìn 6, 7, 8) 


\section{Nghiên cúu - Úng dụng}

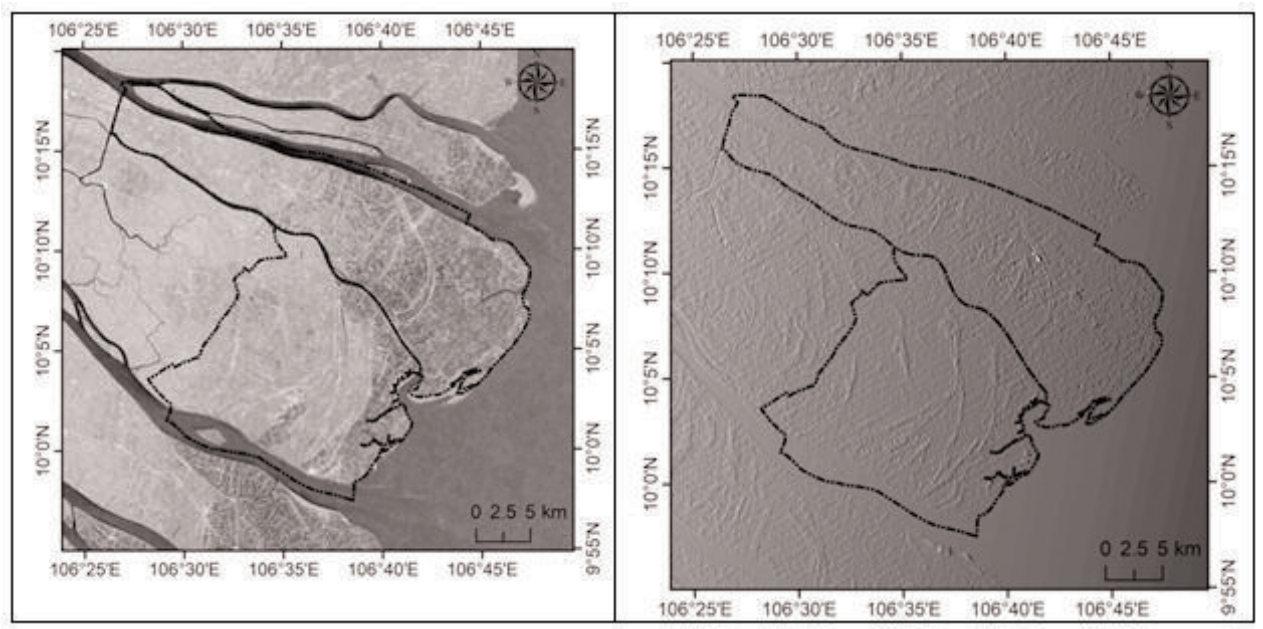

Hình 3: Anh tán xạ ngược, phân cực VV và góc tới cuc bộ của ảnh Sentinel-1 thu ngày 25 tháng 4 năm 2019 khu vục nghiên cưu

Bảng 1: Số liệu chiết tách tù ảnh vệ tinh Sentinel-1 (thu ngày 25 tháng 4 năm 2019) cho các phân cưc tuoong ưng và giá trị độ ẩm đất được đo trong phòng thí nghiệm

\begin{tabular}{|c|c|c|c|c|c|}
\hline \multirow[b]{2}{*}{$\mathrm{N}^{\circ}$} & \multicolumn{2}{|c|}{ Tọa độ điểm đo } & \multirow{2}{*}{$\begin{array}{c}\text { Số hiệu } \\
\text { điểm }\end{array}$} & \multirow[t]{2}{*}{ Sigma0_VV(dB) } & \multirow{2}{*}{$\begin{array}{c}\text { Độ ẩm đất } \\
(\%)\end{array}$} \\
\hline & $X$ & $Y$ & & & \\
\hline 1 & 681796.000 & 1115046.000 & BT01 & -11.21 & 21.10 \\
\hline 2 & 680744.000 & 1111570.000 & BT02 & -12.71 & 27.40 \\
\hline 3 & 678977.000 & 1105184.000 & BT03 & \begin{tabular}{|l|}
-7.03 \\
\end{tabular} & 57.63 \\
\hline 4 & 678502.000 & 1119643.000 & BT04 & -10.25 & 42.76 \\
\hline 5 & 678219.000 & 1115229.000 & BT05 & -9.32 & 31.80 \\
\hline 6 & 666822.000 & 1111074.000 & BT06 & -13.73 & 23.04 \\
\hline 7 & 665063.000 & 1128276.000 & BT07 & -10.01 & 41.79 \\
\hline 8 & 681000.000 & 1106000.000 & BT08 & -6.1 & 66.53 \\
\hline 9 & 675970.000 & 1109505.000 & ВT09 & -7.49 & 47.95 \\
\hline 10 & 668984.000 & 1125045.000 & BT10 & -11.01 & 29.55 \\
\hline 11 & 664520.000 & 1116526.000 & BT11 & -10.68 & 39.11 \\
\hline 12 & 670743.000 & 1113859.000 & BT12 & -5.1 & 64.50 \\
\hline 13 & 668693.000 & 1115521.000 & BT13 & -7.55 & 64.57 \\
\hline 14 & 673201.000 & 1120927.000 & BT14 & -9.56 & 46.52 \\
\hline 15 & 674118.000 & 1107498.000 & BT15 & -9.12 & 38.47 \\
\hline 16 & 690047.000 & 1125046.000 & BĐ06 & -8.69 & 50.89 \\
\hline 17 & 686800.000 & 1123800.000 & ВĐ07 & -12.87 & 28.99 \\
\hline 18 & 684000.000 & 1122000.000 & BĐ08 & -6.02 & 61.93 \\
\hline 19 & 679169.000 & 1127423.000 & ВĐ09 & -9.36 & 30.22 \\
\hline 20 & 684994.000 & 1127705.000 & BĐ10 & -8.02 & 41.79 \\
\hline 21 & 694604.000 & 1118059.000 & BĐ11 & -7.85 & 62.90 \\
\hline 22 & 674239.000 & 1130943.000 & BĐ12 & -7.79 & 43.88 \\
\hline 23 & 668494.000 & 1133621.000 & BĐ13 & -5.48 & 64.60 \\
\hline 24 & 683271.000 & 1125643.000 & BĐ14 & -11.6 & 39.60 \\
\hline 25 & 664626.000 & 1133198.000 & BĐ15 & -6.66 & 63.33 \\
\hline
\end{tabular}

\section{2. Đánh giá kết quả thục nghiệm}

Từ phương trình (1), sử dụng các phần mềm Envi 5.3, ArcGis và Excel tiến hành chiết xuất giá trị độ ẩm trên ảnh Sentinel 1 để đánh giá độ chính xác của mô hình với 5 điểm kiểm tra. Kết quả như sau: (Xem bảng 2)
Qua kết quả kiểm tra các vị trí đo độ ẩm đất trên thực địa tại khu vực huyện $\mathrm{Ba}$ Tri và Bình Đại so sánh với kết quả độ ẩm đất chiết xuất trực tiếp trên ảnh vệ tinh Sentinel 1 cho thấy việc cung cấp giá trị độ ẩm đất bằng ảnh Sentinel có độ chính xác tương đối cao (bảng 3.2). Từ đây,có thể thấy độ tin cậy của mô hình tính độ ẩm đất 


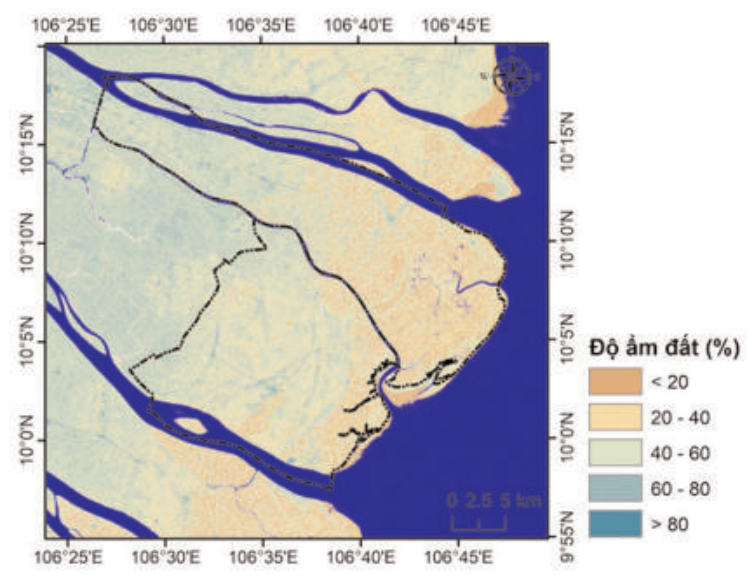

Hình 6: Kết quả độ ẩm đất được tính tì dũ liệu ảnh vệ tinh Sentinel-1 (phân cực VV, chup ngày 25 tháng 4 năm 2019)

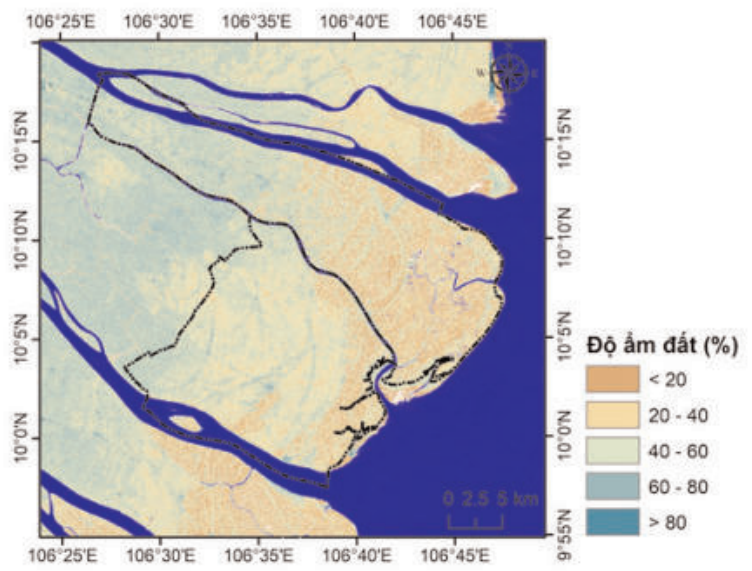

Hình 7: Kết quả độ ẩm đất được tính tù dĩ liệu ảnh vệ tinh Sentinel-1 (phân cưc VV, chup ngày 24 tháng 4 năm 2018)

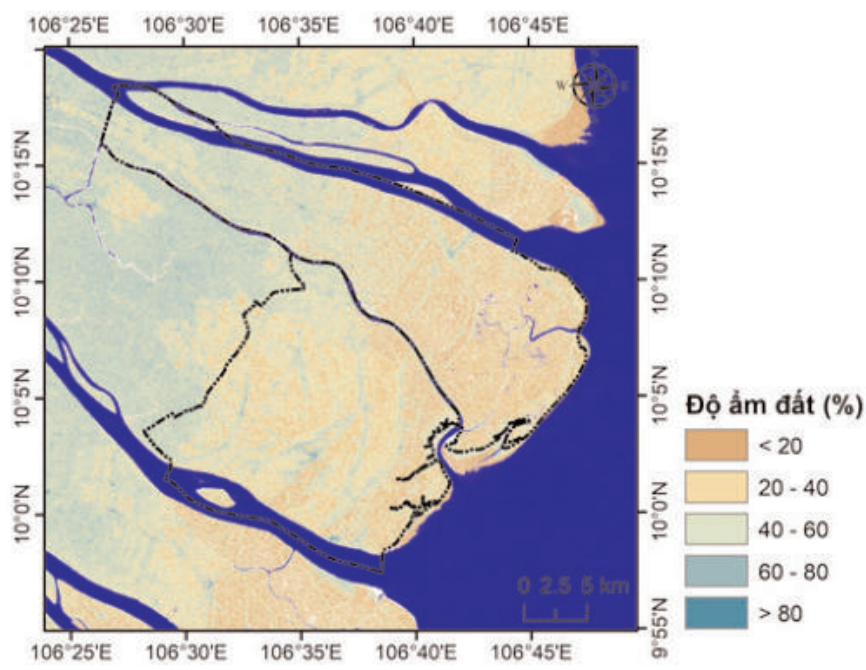

Hình 8: Kết quả độ ẩm đất được tính tù dũ liệu ảnh vệ tinh Sentinel-1 (phân cực VV, chụp ngày 22 tháng 4 năm 2016)

Bảng 2: So sánh kết quả tính toán độ ẩm được chiết xuất tù ảnh Sentinel 1 và kết quả đo đạc trục tiếp ngoài thục địa

\begin{tabular}{|c|c|c|c|c|c|c|}
\hline \multirow[b]{2}{*}{$\mathrm{N}^{\circ}$} & \multicolumn{2}{|c|}{ Tọa độ điểm đo } & \multirow{2}{*}{$\begin{array}{c}\text { Số hiệu } \\
\text { điểm }\end{array}$} & \multirow{2}{*}{$\begin{array}{c}\text { Độ ẩm đất (\%) } \\
\text { đo đạc trong } \\
\text { PTN }\end{array}$} & \multirow{2}{*}{$\begin{array}{l}\text { Độ ẩm đất } \\
\text { (\%) trên ảnh }\end{array}$} & \multirow[t]{2}{*}{ Độ lệch } \\
\hline & $X$ & $Y$ & & & & \\
\hline 1 & 689312.000 & 1112662.000 & $\mathrm{BĐ01}$ & 23.04 & 31.38 & -8.34 \\
\hline 2 & 691000.000 & 1114000.000 & $\mathrm{BĐ02}$ & 38.47 & 38.95 & -0.48 \\
\hline 3 & 687232.000 & 1114961.000 & $\mathrm{BĐ03}$ & 41.23 & 45.808 & -4.578 \\
\hline 4 & 689524.000 & 1119912.000 & $\mathrm{BĐ04}$ & 46.52 & 52.936 & -6.416 \\
\hline 5 & 693000.000 & 1124000.000 & $\mathrm{BĐ05}$ & 54.31 & 43.432 & 10.878 \\
\hline
\end{tabular}


được xây dựng từ dữ liệu đo đạc độ ẩm từ thực địa và dữ liệu ảnh vệ tinh Sentinel 1.

\section{Kết luận}

Trong nghiên cứu này, một mô hình thực nghiệm đã được phát triển để thành lập bản đồ độ ẩm đất từ dữ liệu Sentinel-1 SAR. Để xây dựng mô hình, phương pháp hồi quy tuyến tính đã được sử dụng, các hàm hồi quy tuyến tính và giá trị độ tương quan $\left(\mathrm{R}^{2}\right)$ đồng thời tính toán để đánh giá mối tương quan giữa giá trị độ ẩm đất với giá trị phản xạ ngược trên các kênh ảnh tương ứng (phân cực $\mathrm{VV}$, phân cực $\mathrm{VH}$ và góc tới cục bộ tham chiếu PLIA).

Dữ liệu ảnh vệ tinh chụp ngày 25 tháng 4 năm 2019 và giá trị độ ẩm đất được đo cùng và gần thời điểm với thời điểm chụp ảnh đã được sử dụng để xây dựng mô hình thực nghiệm. Kết quả nghiên cứu cho thấy ảnh phân cực VV có tương quan cao với độ ẩm đất $\left(\mathrm{R}^{2}=0.75\right)$. Các ảnh phân cực VH và góc tới cục bộ tham chiếu PLIA gần như không có tương quan với giá trị độ ẩm đất.Bản đồ độ ẩm đất hai thời kỳ (22 tháng 4 năm 2016 và 24 tháng 4 năm 2018) đã được thành lập trên cơ sở sử dụng mô hình thực nghiệm có được từ ảnh Sentinel 1 chụp ngày 25 tháng 4 năm 2019. Kết quả cho thấy, vào thời điểm 22 tháng 4 năm 2016 độ ẩm đất trên khu vực nghiên cứu có giá trị thấp hơn so với ảnh chụp ngày 24 tháng 4 năm 2018 .

\section{Tài liệu tham khảo}

[1]. Aubert, M., Baghdadi, N., Zribi, M., Douaoui, A., Loumagne, C., Baup, F., ... Garrigues, S. (2011). Analysis of TerraSAR-X data sensitivity to bare soil moisture, roughness, composition and soil crust. Remote Sensing of Environment, 115(8), 1801-1810. http://doi.org/10.1016/j.rse.2011.02.021.

[2]. Dubois, P. C., van Zyl, J., and Engman, T. (1995). Measuring soil moisture with imaging radars. IEEE Transactions on Geoscience and Remote Sensing, 33(4), 915-926. http://doi.org/10.1109/36.406677 Esetlili, M. T., and Kurucu, Y. (2016).
[3]. Gao, Q., Zribi, M., Escorihuela, M., and Baghdadi, N. (2017). Synergetic Use of Sentinel-1 and Sentinel-2 Data for Soil Moisture Mapping at $100 \mathrm{~m}$ Resolution. Sensors, 17(9), 1966. http://doi.org/10.3390/s17091966.

[4]. Heilman, J. ., Kanemasu, E. ., Bagley, J. ., and Rasmussen, V. . (1977). Evaluating soil moisture and yield of winter wheat in the Great Plains using Landsat data. Remote Sensing of Environment, 6(4), 315-326. http://doi.org/10.1016/0034-4257(77)90051-7.

[5]. Kseneman, M., Gleich, D., and Potočnik, B. (2012). Soil-moisture estimation from TerraSAR-X data using neural networks. Machine Vision and Applications, 23(5), 937-952. http://doi.org/10.1007/s00138-0110375-3.

[6]. Lievens, H., and Verhoest, N. E. C. (2012). Spatial and temporal soil moisture estimation from RADARSAT-2 imagery over Flevoland, The Netherlands. Journal of Hydrology, 456-457, 44-56.

[7]. Sundara Kumar K., Udaya Bhaskar P., Padmakumari K., 2012: Estimation of land surface temperature to study urban heat island effect using 270 LANDSAT ETM+ image. International journal of Engineering Science and technology, Vol. 4, No. 2, pp. 771-778.

[8]. Trần Thị Vân, Hoàng Thái Lan, Lê Văn Trung, 2009: Phương pháp viễn thám nhiệt trong nghiên cứu phân bố nhiệt độ đô thị. Tạp chí Các Khoa học về Trái Đất, T.31, 2, 168-177.

[9]. Trịnh Lê Hùng, 2014: Nghiên cứu sự phân bố nhiệt độ bề mặt bằng dữ liệu ảnh đa phổ LANDSAT. Tạp chí Các khoa học về Trái Đất, tập 36, số 01, 82-89. $\bigcirc$ 